\title{
Integration of STATCOM and ESS for power system stability improvement
}

\author{
Ibrahim Alhamrouni ${ }^{1}$, Rasyid Ismail ${ }^{2}$, Mohamed Salem ${ }^{3}$, Bazilah Ismail ${ }^{4}$, Awang Jusoh ${ }^{5}$, Tole Sutikno ${ }^{6}$ \\ ${ }^{1,2,4}$ Electrical Engineering Section, Universiti Kuala Lumpur British Malaysian Institute, Malaysia \\ ${ }^{3}$ School of Electrical and Electronic Engineering, Universiti Sains Malaysia, Malaysia \\ ${ }^{5}$ School of Electrical Engineering, Universiti Teknologi Malaysia, Malaysia \\ ${ }^{6}$ Department of Electrical Engineering, Faculty of Industrial Technology, Universitas Ahmad Dahlan, Indonesia
}

\begin{tabular}{l} 
Article Info \\
\hline Article history: \\
Received Nov 8, 2019 \\
Revised Jan 4, 2020 \\
Accepted Feb 14, 2020 \\
\hline
\end{tabular}

\section{Keywords:}

DIgSILENT software

ESS

IEEE 14 bus system

Power system stability

STATCOM

Voltage instability

\begin{abstract}
The power system enters a state of voltage instability due to the inability of the power system to meet the demand for active power and reactive power due to the increase of system load. In order to stabilize the power system, the installation of STATCOM and ESS needs to be performed. The main objective of this paper is to identify the suitable size and location of STATCOM and ESS for power system stability improvement. First, the IEEE 14 bus system was simulated using DIgSILENT software in ideal condition. Then, the system loadability was increased up to $200 \%$ of initial value to locate the weakest bus. This study includes the applicable location and sizing of STATCOM and ESS towards improving power system stability. The results showed that the application of STATCOM and ESS with the most reliable size can increase the bus voltage (p.u and $\mathrm{kV}$ ) of IEEE 14 bus system thus improving the power system stability. For recommendation, the power system stability can be improved by installing multiple STATCOM and ESS at other load buses and applying a controller to both STATCOM and ESS to improve the effectiveness of generating and absorbency of active and reactive power in the power system.
\end{abstract}

This is an open access article under the CC BY-SA license.

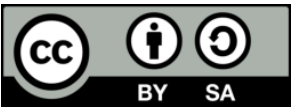

\section{Corresponding Author:}

Ibrahim Alhamrouni,

Electrical Engineering Section,

University Kuala Lumpur British Malaysian Institute (UniKL BMI), Gombak 53100, Malaysia.

Email: ibrahim.mohamed@unikl.edu.my

\section{INTRODUCTION}

The electric power systems have been utilized for decades to fulfil the exponential growth of electrical power demand. This has resulted in a rapid construction of new transmission lines to connect the consumers with electricity. A variety of loads such as induction motor tends to consume reactive power [1-3] and it has altered the system stability thus decreasing the electric power system efficiency. The governments around the globe are trying to improve power system to reduce electricity production cost and boost energy independence [4]. The disturbance of a system due to sudden changes of load, the sudden short circuit and voltage surge. The ability of the power system to return to its normal operating rating after being disturbed is called stability. According to [5], power system stability is the ability of an electric power system, form a given initial operating condition, to recoup a state of operating equilibrium after subjected to a physical disturbance, with bounded system variables to improve practicality. Dong et al [6] added that the power system is highly nonlinear system that works in a constantly changing environment; generator outputs, loads and key operating parameters change frequently. Small-disturbance voltage stability is the system ability to 
retain steady voltages when a small perturbation such as incremental changes in system load occur [7, 8]. Only small-disturbance voltage stability is being investigate in this research.

With the emerging technology of flexible AC transmission system (FACTS) controllers which provide fast and reliable control over voltage angle, magnitude and line impedance such as static synchronous compensators (STATCOM's). According to [1], STATCOM is defined by IEEE as selfcommutated switching power converter supplied from an appropriate electric energy source and operated to produce a set of adjustable multiphase voltage, which may be coupled to an AC power system for the purpose of exchanging independently controllable real and reactive power. STATCOM provide means of significant real power modulation capability [9, 10]. The application of STATCOMs for short-term voltage stability improvement has been proved in many studies with the focus on reactive power control and voltage regulation using Lyapunov-based adaptive controller [11,12] and feedback linearization [13]. A STATCOM generally consists of a DC capacitor, an inverter and a coupling transformer [14]. The correct sizing and placement of STATCOM is importance as it need to be economically feasible and logical to be implemented in the power system. There are several calculations that must be done to determine the parameter of the modelled power system either STATCOM model in steady-state analysis or in the dynamic models [14-16].

The ESS stores energy in form of magnetic field due to the flow of direct current in coil. The energy is stored for a limited time and can be transform back into electricity [17, 18]. It is generally used for short duration energy storage and commonly to improve power quality. The ESS efficiency reduces during energy transformation processes due to storage losses and efficiencies. Energy storage system (ESS) is a type of device used to store electrical energy in certain form and released it when required. The general process of converting the electrical energy is through an energy conversion module (ECM) into a different form or an energy storage medium (ESM) either electrical, mechanical or electrochemical [17, 19]. To obtain the suitable size of ESS, the sufficient power of ESS and its energy capacity must be considered. The number of cycles and SoC of the ESS operation are two main element being analyse to predict the suitable ESS models [20-22]. Capacitor bank energy storage system (CBES) which is a type of energy storage system (ESS) available in DIgSILENT Power Factory Environment. Capacitor bank is a group of several capacitors of the same rating that are connected in series or parallel with each other to store electrical energy. The capacitor bank is utilized because it has the cheapest cost compared to other type of ESS to improve the reactive power of a power system. CBES is used to compensate reactive energy. The appropriate placement can maximize the performance of ESS for peak demand mitigation, power quality improvement, reduction of overall network cost, peak demand mitigation, system effectiveness and RES integration [23, 24].

The combination of STATCOM and ESS allows more reactive power to be absorb, generated and compensated. The STATCOM and ESS are connected to existing system through a coupling transformer. The conventional STATCOM has only two steady state operating modes which are inductive (lagging) and capacitive (leading). The output voltage magnitude and the phase angle of the STATCOM can be controlled but it cannot be independently adjusted as it has no active power. The combination of STATCOM with ESS has extend the operating modes into four which are inductive with dc charge, capacitive with dc charge, inductive with dc charge and capacitive with dc charge. For both charging and discharging modes of ESS, the voltage $\mathrm{dc}$ is assumed to be constant. The voltage source converter will operate as rectifier to receive the energy from utility provider. The suitable location and value for both STATCOM and ESS need to be determined based on the weakest bus location. The weakest bus generally located far from generator buses and interconnecting with other load buses. The model of STATCOM and ESS in IEEE 14 bus system will be simulated by using DIgSILENT Power Factory and the result will be analysed.

\section{STATCOM AND ESS TOPOLOGY}

The STATCOM and ESS are combined to increase the ability of the simulated IEEE 14 bus system in DIgSILENT Power Factory environment to endure any increase in system loadability. The STATCOM is able to inject and absorb reactive power while ESS is used to compensate reactive energy. This system is made up of one slack bus, three generator bus and 10 load bus as shown in Figure 1. The location of STATCOM and ESS will be determined based on the weakest bus location due to voltage drop when the system loadability is increased.

The modelled IEEE 14 bus system is simulated in 4 different case studies. For Case 1, the IEEE 14 bus system is set to be a base and reference case system. The system is simulated in a normal condition with $100 \%$ loadability as standardized by IEEE Standards Association [25]. All the parameter of the components was set as in [25]. The modelled system was designed in DIgSILENT Power Factory Environment to observe the system stability when there is no disturbance in the system which can also be known as an ideal system. For case 2, the value for all components were kept constant except for the general load. The system loadability of the simulated system was increased to $200 \%$ of the standard value from case 1 . The system 
loadability was increased in order to make the system enters an unstable state. The bus voltage p.u and bus voltage $\mathrm{kV}$ of each of the bus was observed and recorded for analysis.

To improve the power system stability, STATCOM and ESS are used in the simulated system to inject and absorb reactive power and to compensate the reactive energy. For case 3 , the STATCOM is being introduced towards simulated system in case 2 . The inclusion of STATCOM is to improve the stability of the modelled system. The STATCOM was included at a suitable location with an acceptable size (value) to increase the stability of the modelled system. The changes in the bus voltage p.u and bus voltage $\mathrm{kV}$ were observed and recorded to be analysis. Meanwhile, for Case 4, the ESS is being introduced towards the simulated system in case 3. The type of ESS chosen is capacitor bank energy storage system (CBES) because of its ability to compensate reactive energy. The CBES was included at an appropriate location with the right size (value) to further increase the stability of the modelled system. The system stability was observed and recorded to be analysis and compared.

The ESS is connected to a bus containing STATCOM and a transformer. The CBES is set as an AC source to compliance the circuit needs by compensate the reactive energy. The rated reactive power set for the capacitor bank is $5 \mathrm{Mvar}$ with $7 \%$ degree. The nominal voltage for the capacitor bank is $0.4 \mathrm{kV}$ and the capacitor bank is using an AC system type setting. Meanwhile, the control mode of the STATCOM is Vdc-Q. The reactive power setpoint of the chosen STATCOM is 38 Mvar with control mode of Vdc-Q. The DC voltage setpoint of the STATCOM is 1 p.u with capability curved of -400 Mvar minimum and 400 Mvar maximum. The reactive power limit can be controlled using the user interface and it can be freely modified. The simulation in DIgSILENT Power Factory software use Newton-Raphson method to accurately calculate the load flow of bus voltage p.u and bus voltage $\mathrm{kV}$ at each of the bus.

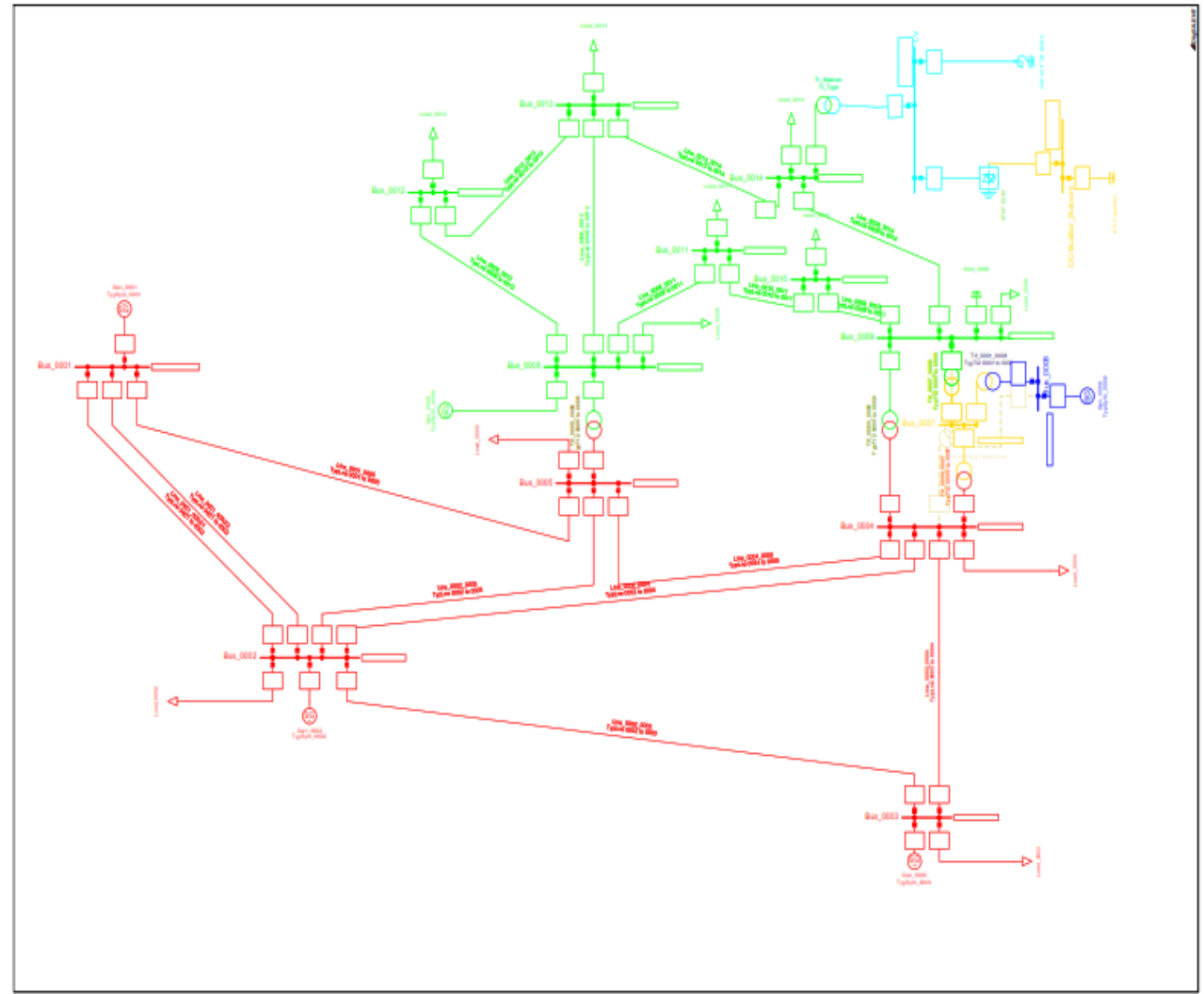

Figure 1. The IEEE 14 bus system with STATCOM and ESS in DIgSILENT

\section{NEWTON-RAPHSON POWER FLOW ALGORITHM}

Newton-Raphson power flow algorithm is an efficient algorithm to solve non-linear equation. It transforms the procedure of solving nonlinear equations into the procedure of repeatedly solving linear equations which is known as linearization. A system of $n$ non-linear equations with $n$ unknowns is defined as: 


$$
\begin{aligned}
& f(x)=\left[\begin{array}{c}
f_{1}(x) \\
f_{2}(x) \\
\vdots \\
f_{3}(x)
\end{array}\right]=\left[\frac{P(x)}{Q(x)}\right]=\left[\begin{array}{c}
P_{2}(x) \\
\vdots \\
\frac{P_{n}(x)}{Q_{2}(x)} \\
\vdots \\
Q_{n}(x)
\end{array}\right] \\
& x=\left[\begin{array}{l}
\delta \\
V
\end{array}\right]=\left[\begin{array}{c}
\delta_{2} \\
\vdots \\
\delta_{n} \\
V_{2} \\
\vdots \\
V_{n}
\end{array}\right]
\end{aligned}
$$

Where, the $f(x)$ is the function of P (PV and PQ bus) and Q (PQ bus) with variable of $x$. In this case $x$ is $\mathrm{V}$ and $\boldsymbol{\delta}$ for (Slack, PV and PQ bus). All P, Q and V terms are in per unit and $\boldsymbol{\delta}$ term are in degree. The variables for Slack bus $(V 1$ and $\delta 1)$ are omitted since they already known as $\left(1 \angle 0^{\circ}\right)$.

Set the tolerance value and number of iterations. Specify all the admittance data and bus type. Let $x^{0}$ be the initial guess value (for unknown value of V (PQ bus) and $\boldsymbol{\delta}$ (PV and PQ bus).

$$
x^{0}=\left[\begin{array}{l}
V^{0} \\
\delta^{0}
\end{array}\right]
$$

Form the power balance equation and substitute in the initial guess value (from Step 1) into $(x)$ to determine new approximate value, $f(x)^{i}$ which is $(k)$ and $\boldsymbol{Q}(k)$.

$$
\begin{aligned}
& P_{k}=V_{k} \sum_{n=1}^{N} V_{n}\left[G_{k n} \cos \left(\delta_{k}-\delta_{n}\right)+B_{k n} \sin \left(\delta_{k}-\delta_{n}\right)\right] \\
& Q_{k}=V_{k} \sum_{n=1}^{N} V_{n}\left[G_{k n} \sin \left(\delta_{k}-\delta_{n}\right)-B_{k n} \cos \left(\delta_{k}-\delta_{n}\right)\right] \\
& \text { Where, k=2,3,.., N. }
\end{aligned}
$$

Form the Jacobian matrix $(\mathrm{J})$ that contains $\mathrm{n} \times \mathrm{n}$ matrix. The elements in $\mathrm{J}$ are the partial derivatives of $f(x)^{i}$, where $\mathrm{i}$ is the value of current iteration. The Jacobian matrix, $\mathrm{J}$ can be expended as (6).

$$
J^{i}=\left.\frac{d f}{d x}\right|_{x=x(i)}=\left[\begin{array}{cccc}
\frac{\partial f_{1}}{\partial x_{1}} & \frac{\partial f_{1}}{\partial x_{1}} & \cdots & \frac{\partial f_{1}}{\partial x_{n}} \\
\frac{\partial f_{2}}{\partial x_{1}} & \frac{\partial f_{2}}{\partial x_{2}} & \cdots & \frac{\partial f_{2}}{\partial x_{n}} \\
\vdots & \vdots & \ddots & \vdots \\
\frac{\partial f_{n}}{\partial x_{1}} & \frac{\partial f_{n}}{\partial x_{n}} & \cdots & \frac{\partial f_{n}}{\partial x_{n}}
\end{array}\right]_{x=x(i)}
$$

For nonlinear system, the equation of $\mathrm{y}=\mathrm{Ax}$ is arranged as shown below,

$$
J \cdot \Delta x=\Delta f(x)
$$

$$
\left[\begin{array}{ll}
J 1^{i} & J 2^{i} \\
J 3^{i} & J 4^{i}
\end{array}\right]\left[\begin{array}{l}
\Delta \delta^{i} \\
\Delta V^{i}
\end{array}\right]=\left[\begin{array}{l}
\Delta P^{i} \\
\Delta Q^{i}
\end{array}\right]
$$

Calculate the new $\Delta \boldsymbol{\delta}$ and $\Delta \boldsymbol{V}$, using any method to solve matrix such as Cramer's Rule, Gauss Elimination, LU Decomposition.

$$
\left[\begin{array}{l}
\Delta \delta^{i} \\
\Delta V^{i}
\end{array}\right]=\left[\begin{array}{ll}
J 1^{i} & J 2^{i} \\
J 3^{i} & J 4^{i}
\end{array}\right]^{-1}\left[\begin{array}{l}
\Delta P^{i} \\
\Delta Q^{i}
\end{array}\right]
$$

Calculate the new $\boldsymbol{\delta}$ and $\boldsymbol{V}$,

$$
\left[\begin{array}{l}
\delta^{i+1} \\
V^{i+1}
\end{array}\right]=\left[\begin{array}{l}
\delta^{i} \\
V^{i}
\end{array}\right]+\left[\begin{array}{l}
\Delta \delta^{i} \\
\Delta V^{i}
\end{array}\right]
$$


Calculate the power flow (both real and reactive power) for each line,

$$
S_{k n}=P_{k n}+j Q_{k n}=V I^{*}=\frac{V_{k}\left(V_{k}-V_{n}\right)^{*}}{Z_{k n}{ }^{*}}
$$

\section{RESULTS AND ANALYSIS}

The simulation was run with $100 \%$ loadability for case $1,200 \%$ loadability for case $2,200 \%$ loadability with STATCOM at bus 14 for case 3 and 200\% loadability with STATCOM and ESS at bus 14 for case 4. Only the parameter of bus voltage (p.u and $\mathrm{kV}$ ) are being monitored and compared during research. The STATCOM is used to generate and absorb reactive power while the ESS is used to compensate reactive energy. The need for application of STATCOM and ESS for power system stability improvement are being considered in these studies.

\subsection{Result for Case 1}

In case 1, the simulated system is set as an ideal system with no disturbance as a reference. The simulated IEEE 14 bus system was run with 100\% loadability without STATCOM and ESS. The bus voltage (p.u) and bus voltage $(\mathrm{kV})$ were monitored during the simulation.

Figure 2 shows the bus voltage (p.u) for case 1. Bus 1 and bus 3 has the highest voltage (p.u) at 1.050 p.u and 1.040 p.u respectively. Meanwhile, bus 9, bus 10, bus 13 and bus 14 are monitored. According to [26] bus 14 is identified as the weakest bus.

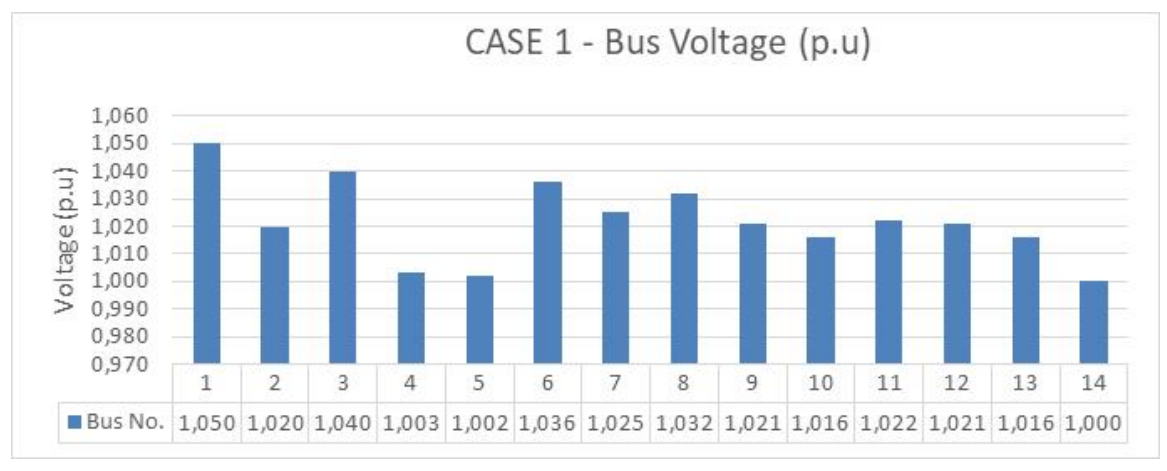

Figure 2. Bus voltage (p.u) in case 1

Figure 3 shows the bus voltage $(\mathrm{kV})$ for case 1 . Bus 1 has the highest voltage $(\mathrm{kV})$ at $138.6 \mathrm{kV}$ and bus 3 has the second highest voltage $(\mathrm{kV})$ at $137.2 \mathrm{kV}$. The load bus mainly has higher than $33 \mathrm{kV}$ rating. The voltage $(\mathrm{kV})$ at bus 9 , bus 10 , bus 11 , bus 12 , bus 13 , and bus 14 are $33.70 \mathrm{kV}, 33.54 \mathrm{kV}, 33.74 \mathrm{kV}$, $33.68 \mathrm{kV}, 33.52 \mathrm{kV}$ and $33.01 \mathrm{kV}$ respectively.

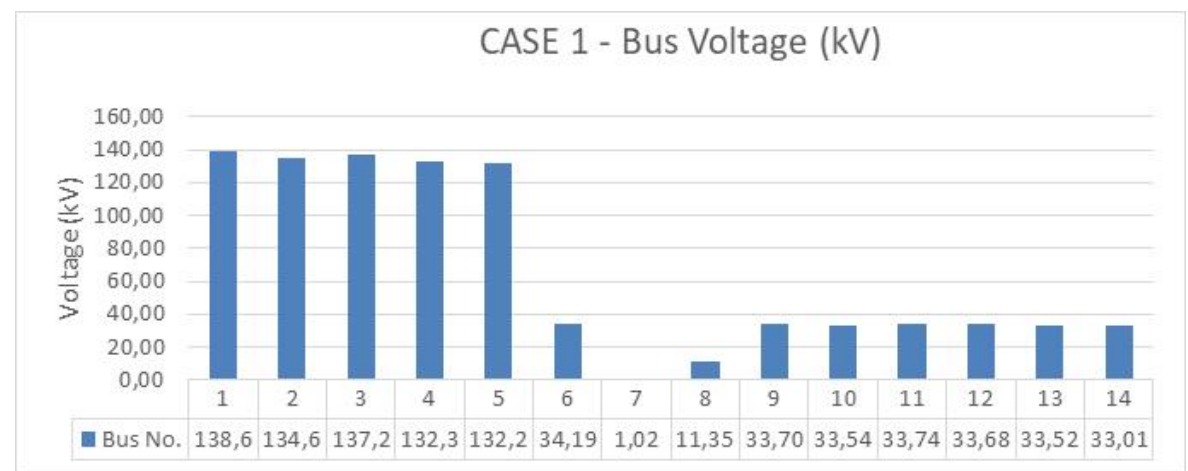

Figure 3. Bus voltage $(\mathrm{kV})$ in case 1 


\subsection{Result for Case 2}

In case 2 , the simulated IEEE 14 bus system was run with $200 \%$ loadability without STATCOM and ESS. The bus voltage (p.u) and bus voltage $(\mathrm{kV})$ were monitored during the simulation.

Figure 4 shows the bus voltage (p.u) for case 2. Bus 1 and bus 3 has the highest voltage (p.u) at 1.050 p.u and 1.040 p.u respectively. Meanwhile, bus 9, bus 10, bus 13 and bus 14 are 0.965 p.u, 0.962 p.u, 0.988 p.u and 0.935 p.u respectively. The bus 14 has the lowest bus voltage (p.u) after the system loadability is increase to $200 \%$. Therefore, it can be classified as the weakest bus.

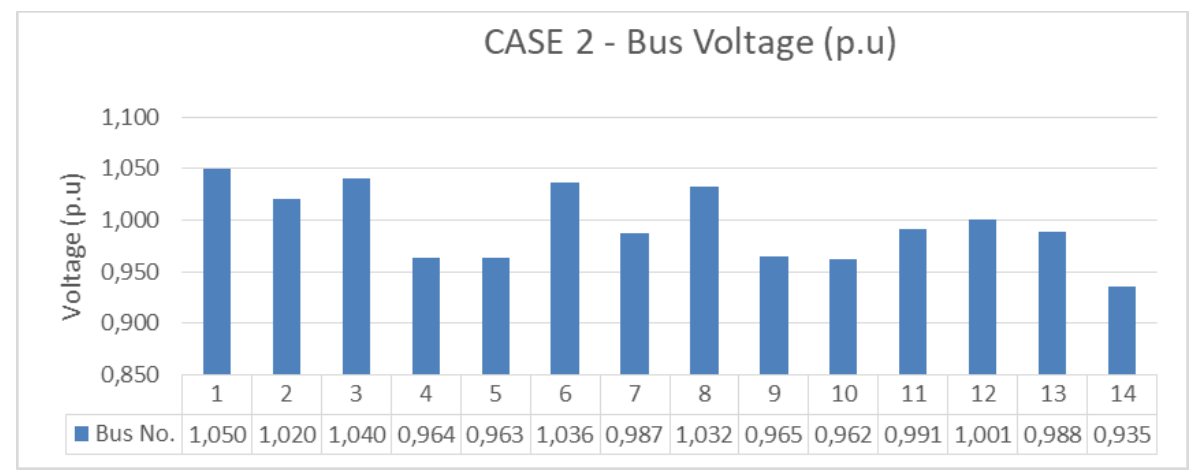

Figure 4. Bus voltage (p.u) in case 2

Figure 5 shows the bus voltage $(\mathrm{kV})$ for case 2 . Bus 1 has the highest voltage $(\mathrm{kV})$ at $138.6 \mathrm{kV}$ and bus 3 has the second highest voltage $(\mathrm{kV})$ at $137.2 \mathrm{kV}$. The majority of load bus has lower bus voltage $(\mathrm{kV})$ than $33 \mathrm{kV}$ rating except for bus 4 , bus 5 and bus 12 . The voltage $(\mathrm{kV})$ at bus 9 , bus 10 , bus 11 , bus 12 , bus 13 , and bus 14 are $31.85 \mathrm{kV}, 31.73 \mathrm{kV}, 32.69 \mathrm{kV}, 33.04 \mathrm{kV}, 32.59 \mathrm{kV}$ and $30.84 \mathrm{kV}$ respectively.

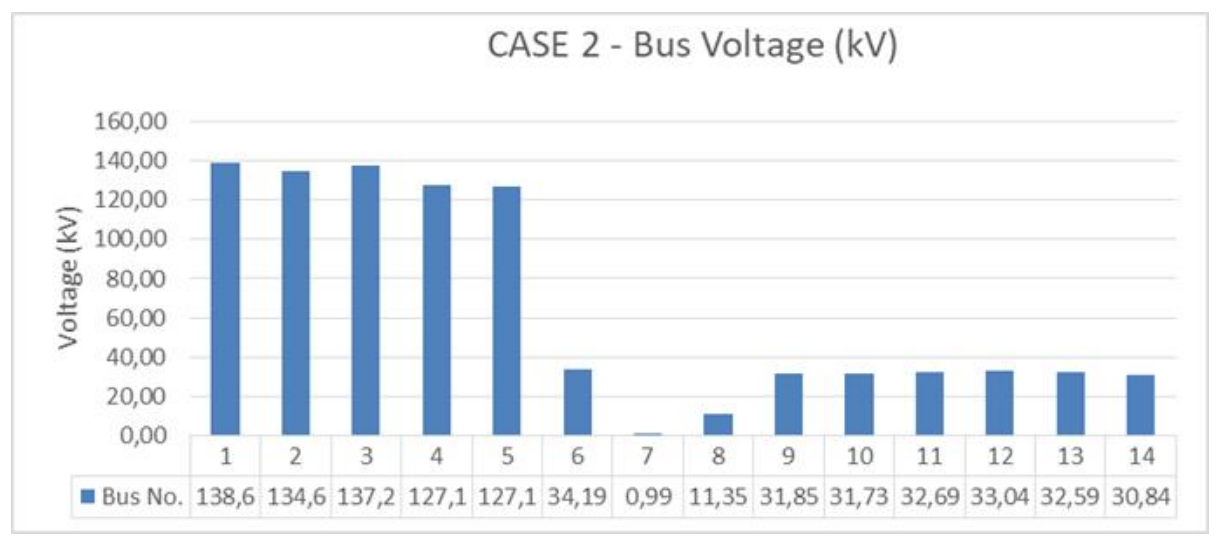

Figure 5. Bus voltage $(\mathrm{kV})$ in case 2

\subsection{Result for Case 3}

In case 3, the simulated IEEE 14 bus system was run with $200 \%$ loadability with STATCOM at bus 14. The bus voltage (p.u) and bus voltage (kV) were monitored during the simulation.

Figure 6 shows the bus voltage (p.u) for case 3. Bus 1 and bus 3 has the highest voltage (p.u) at 1.050 p.u and 1.040 p.u respectively. Meanwhile, bus 9 , bus 10 , bus 13 and bus 14 are 0.982 p.u, 0.976 p.u, 0.999 p.u and 0.985 p.u respectively. The voltage $(\mathrm{kV})$ of bus 14 increase considerable after STATCOM is installed at bus 14. Figure 7 shows the bus voltage $(\mathrm{kV})$ for case 3 . Bus 1 has the highest voltage $(\mathrm{kV})$ at $138.6 \mathrm{kV}$ and bus 3 has the second highest voltage $(\mathrm{kV})$ at $137.2 \mathrm{kV}$. The majority of load bus has bus voltage $(\mathrm{kV})$ closed to $33 \mathrm{kV}$ rating except for bus 4 and bus 5 . The voltage $(\mathrm{kV})$ at bus 9 , bus 10 , bus 11 , bus 12 , bus 13 , and bus 14 are $32.41 \mathrm{kV}, 32.20 \mathrm{kV}, 32.93 \mathrm{kV}, 33.24 \mathrm{kV}, 32.97 \mathrm{kV}$ and $32.51 \mathrm{kV}$ respectively. 


\subsection{Result for Case 4}

In case 4 , the simulated IEEE 14 bus system was run with $200 \%$ loadability with STATCOM and ESS at bus 14. The bus voltage (p.u), bus voltage $(\mathrm{kV})$ and bus voltage (deg) were monitored during the simulation.

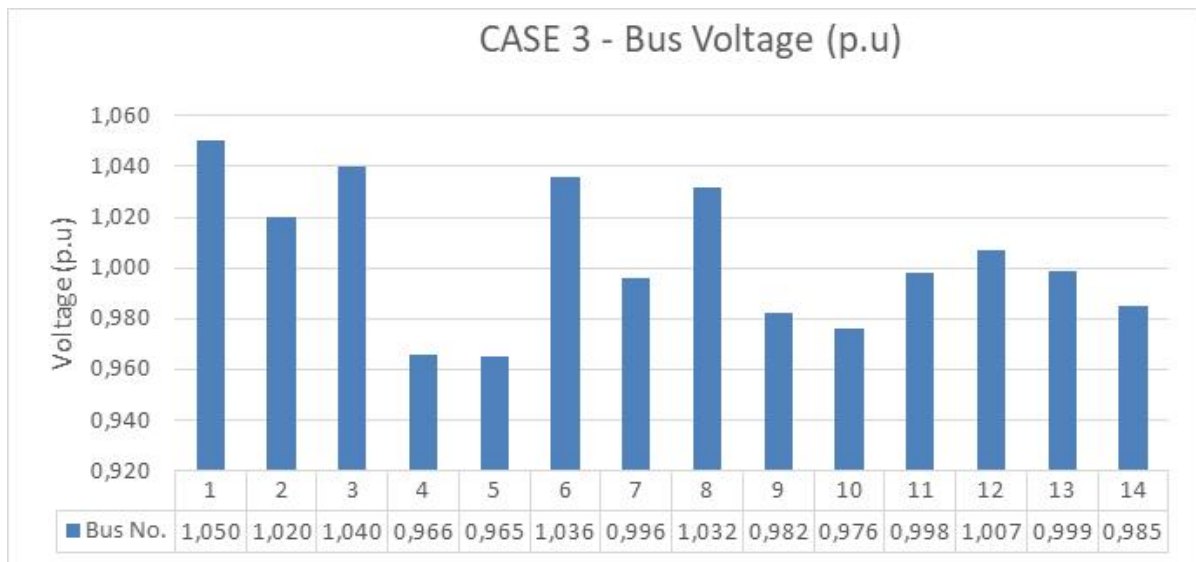

Figure 6. Bus voltage (p.u) in case 3

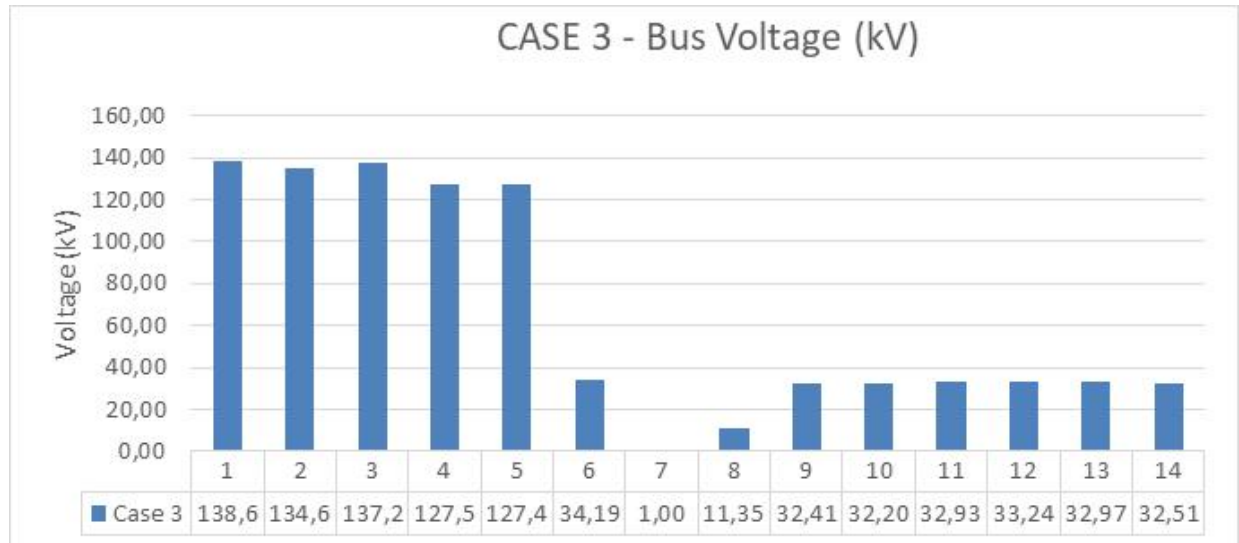

Figure 7. Bus voltage $(\mathrm{kV})$ in case 3

Figure 8 shows the bus voltage (p.u) for case 4. Bus 1 and bus 3 has the highest voltage (p.u) at 1.050 p.u and 1.040 p.u respectively. Meanwhile, bus 9, bus 10, bus 13 and bus 14 are 0.987 p.u, 0.980 p.u, 1.002 p.u and 1.000 p.u respectively. The voltage $(\mathrm{kV})$ of bus 14 increase considerable after STATCOM and ESS is installed at bus 14. The bus located closed to bus 14 also gain increase up to 1.009 p.u at bus 12 . Figure 9 shows the bus voltage $(\mathrm{kV})$ for case 4 . Bus 1 has the highest voltage $(\mathrm{kV})$ at $138.6 \mathrm{kV}$ and bus 3 has the second highest voltage $(\mathrm{kV})$ at $137.2 \mathrm{kV}$. The majority of load bus has bus voltage $(\mathrm{kV})$ at or closed to 33 $\mathrm{kV}$ rating except for bus 4 and bus 5 . The voltage $(\mathrm{kV})$ at bus 9 , bus 10 , bus 11 , bus 12 , bus 13 , and bus 14 are $32.58 \mathrm{kV}, 32.33 \mathrm{kV}, 33.00 \mathrm{kV}, 33.30 \mathrm{kV}, 33.08 \mathrm{kV}$ and $33.00 \mathrm{kV}$ respectively.

\subsection{Result Comparison and Discussion}

Figure 10 shows the comparison of bus voltage (p.u) for load buses. Bus 14 has the highest different in voltage (p.u) which is 0.065 p.u before and after applying STATCOM and ESS because the STATCOM and ESS are being applied at bus 14. The rating for STATCOM is 38 Mvar while the rating of the ESS is 5 Mvar. Bus 9, bus 10 and bus 13 are second, third and fourth highest different in voltage (p.u). This is due to the location of bus 9 and 10 in line with bus 14 and no generator located closed to each of the bus. Bus 13 is place fourth because it was connected to a generator bus which is bus 6 . Bus 4 and bus 5 has the lowest 
different in voltage (p.u) which are at 0.003 p.u. Both buses are located far from bus 14 , thus the effectiveness of STATCOM and ESS are diminish.

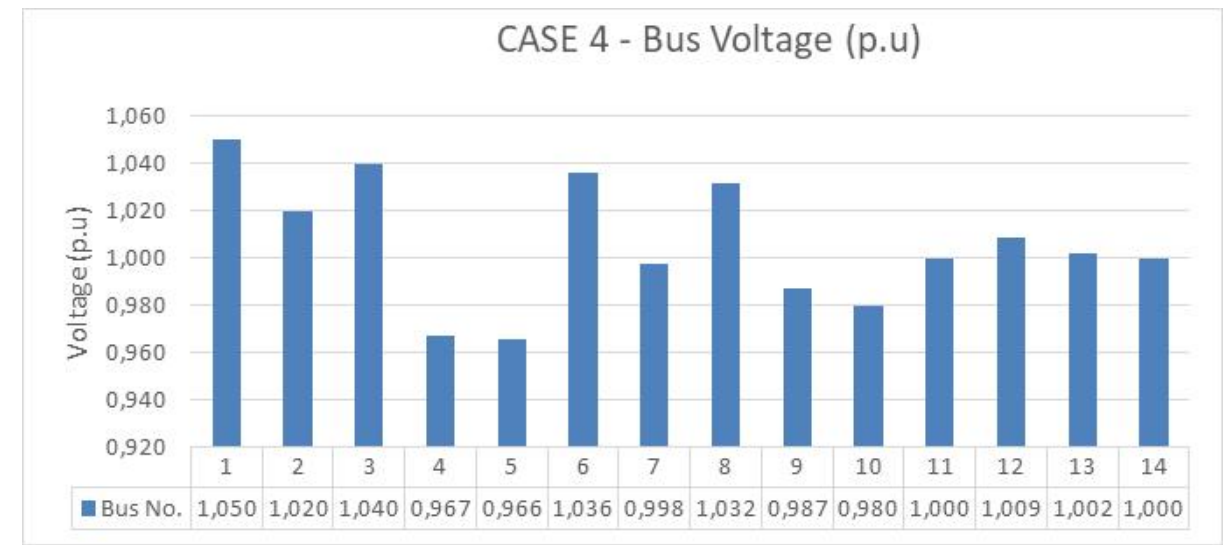

Figure 8. Bus voltage (p.u) in case 4

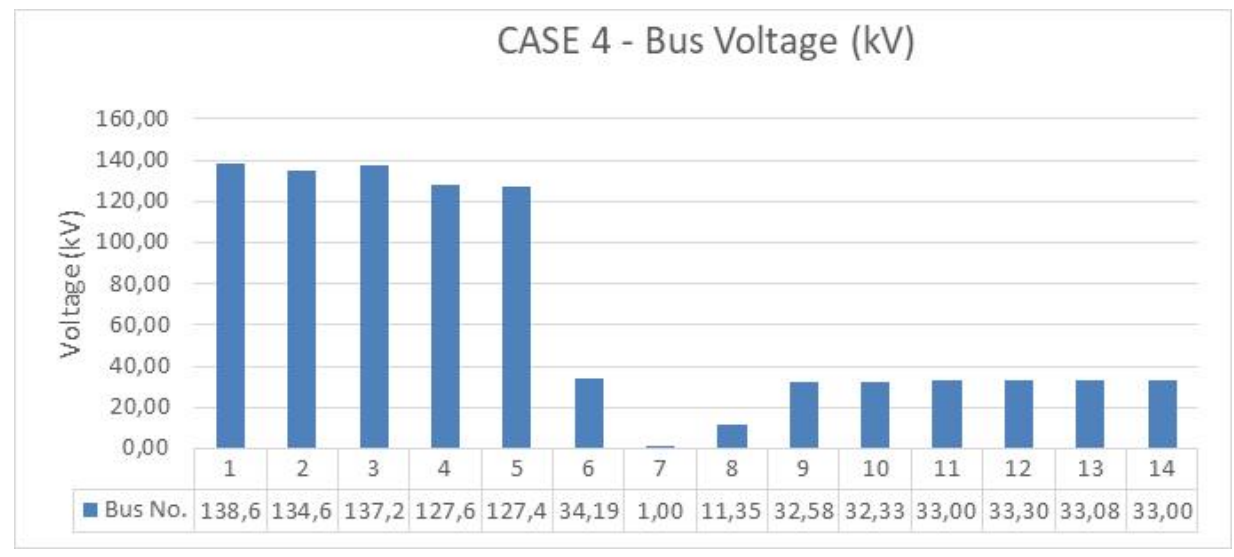

Figure 9. Bus voltage $(\mathrm{kV})$ in case 4

\subsection{Results Comparison and Discussion}

Figure 10 shows the comparison of bus voltage (p.u) for load buses. Bus 14 has the highest different in voltage (p.u) which is 0.065 p.u before and after applying STATCOM and ESS because the STATCOM and ESS are being applied at bus 14. The rating for STATCOM is 38 Mvar while the rating of the ESS is 5 Mvar. Bus 9, bus 10 and bus 13 are second, third and fourth highest different in voltage (p.u). This is due to the location of bus 9 and 10 in line with bus 14 and no generator located closed to each of the bus. Bus 13 is place fourth because it was connected to a generator bus which is bus 6 . Bus 4 and bus 5 has the lowest different in voltage (p.u) which are at 0.003 p.u. Both buses are located far from bus 14, thus the effectiveness of STATCOM and ESS are diminish.

Figure 11 shows the bus voltage $(\mathrm{kV})$ comparison for load buses. There are small changes of bus voltage $(\mathrm{kV})$ from case 2 to case 4 . The rated bus voltage $(\mathrm{kV})$ for most load buses are $132 \mathrm{kV}$ and $33 \mathrm{kV}$. Bus 9 , bus 10 , bus 11 , bus 13 and bus 14 initially rated at above $33 \mathrm{kV}$. When the system loadability was increased to $200 \%$, the bus voltage $(\mathrm{kV})$ for each of load busses decreases. After the installation of STATCOM and ESS at bus 14 , the bus voltage $(\mathrm{kV})$ of load buses increases at least more than $33 \mathrm{kV}$. Bus 14 however has higher voltage $(\mathrm{kV})$ compared to initial value due to the power generated from STATCOM and ESS. The bus voltage does not drop heavily and the system does not collapse after the loadability was increase by $200 \%$ because the IEEE 14 bus system is a strong system with 4 generators and only 9 general loads. The system is also not widely interconnected like some other systems and the available generation units prevent any possible collapse even though the loadability has been increased greatly. 


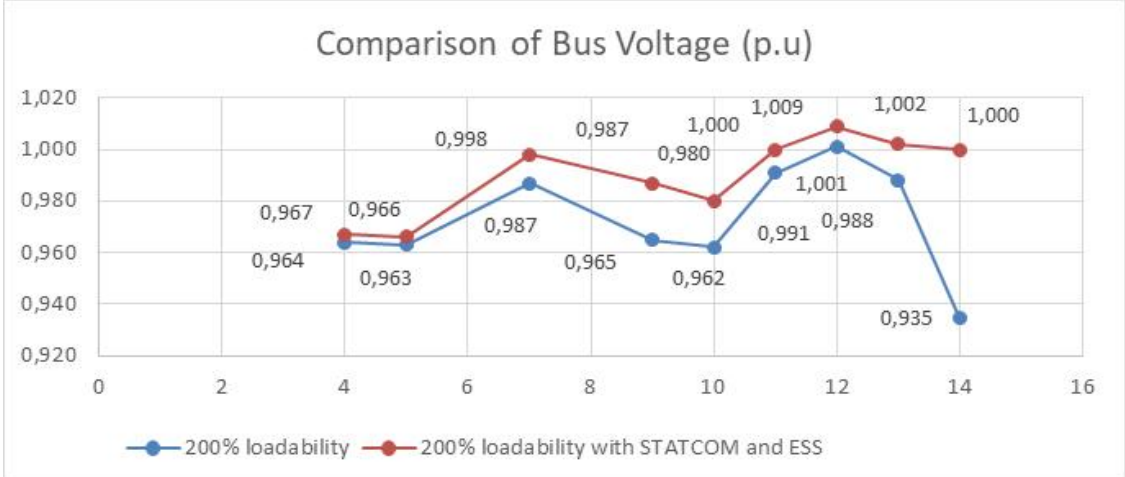

Figure 10. The bus voltage (p.u) comparison for load buses

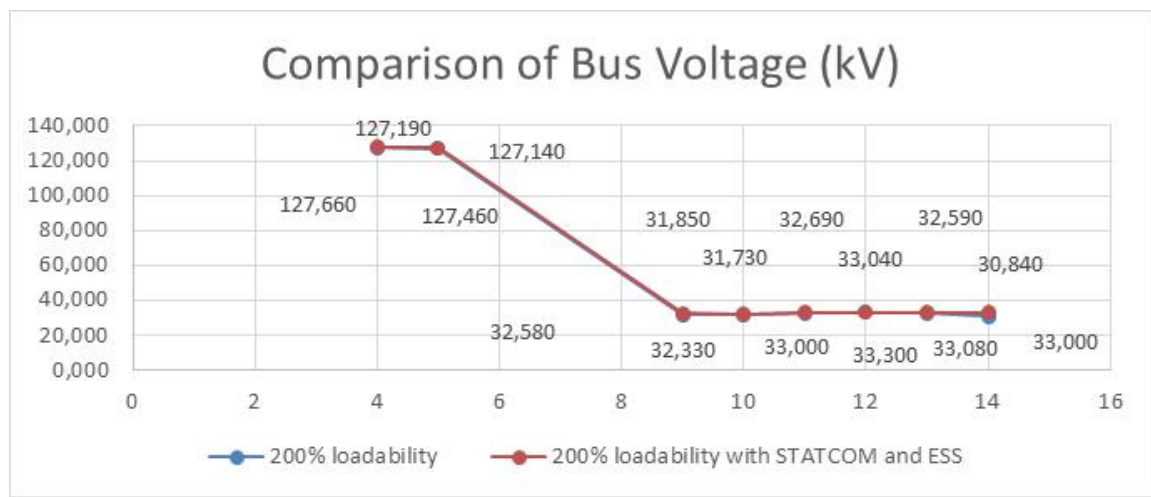

Figure 11. The bus voltage $(\mathrm{kV})$ comparison for load buses

\subsection{Comparison with Previous Studies}

Figure 12 shows the bus voltage (p.u) of this study and previous studies. The load buses in all studies are different from each other. Generally, the installation of STATCOM and ESS at bus 14 in this study is noticeable better compare to only the application of STATCOM in [26, 27].The bus voltage (p.u) in this study at bus 10 is 0.167 p.u higher compare to [27]. At the voltage (p.u) of bus 11 this study is at 1.000 p.u while [26, 27] at 0.990 p.u and 0.927 p.u respectively. At bus 12, the bus voltage in this study is at 1.009 p.u while both bus voltage (p.u) in $[26,27]$ is lower than 1.000 p.u. At bus 13 , the bus voltage in this study is 0.002 p.u and 0.041 p.u higher than $[26,27]$ respectively. At bus 14, both this study and [26] obtained 1.000 p.u while [27] only obtain 0.815 p.u.

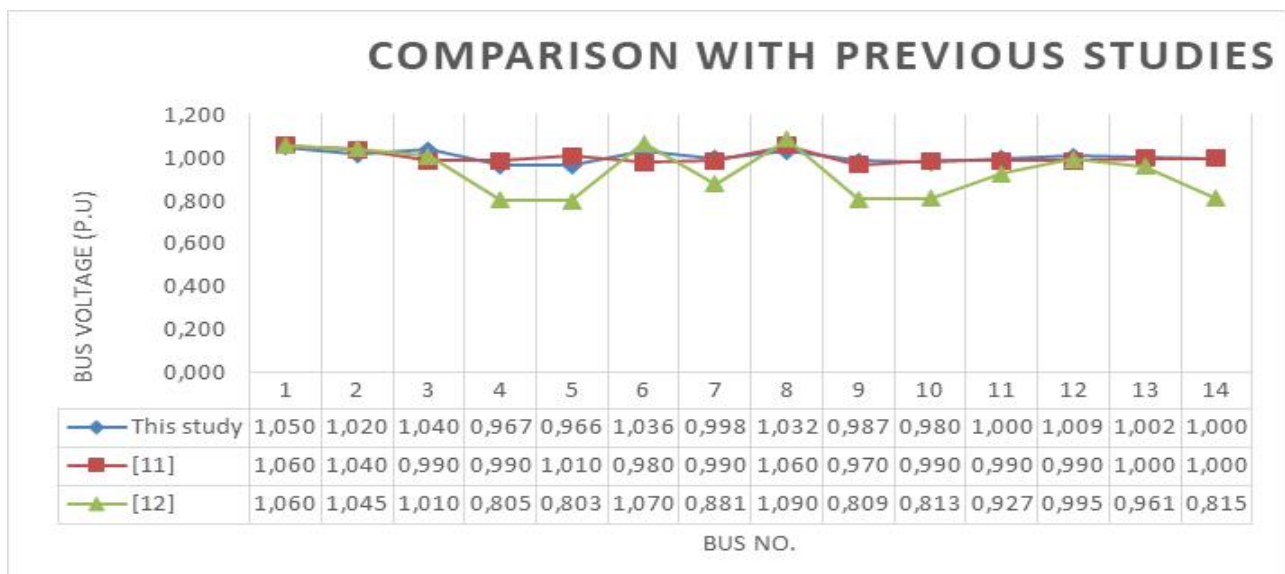


Figure 12. The comparison between this study and previous studies

This analysis has proof that the installation of both STATCOM and ESS is comparably better than only the application of STATCOM. The installation of STATCOM and ESS is at bus 14 as it is the weakest bus and the most vulnerable towards loadability changes. This is due to the location of bus 14 far from generator and being interconnected to other load buses.

\section{CONCLUSION}

The installation of STATCOM and ESS at bus 14 with 38 Mvar and 5 Mvar respectively has successfully improve the system stability. The voltage (p.u) and voltage $(\mathrm{kV})$ at bus 14 have been improved significantly from 0.935 p.u to 1.000 p.u and $30.840 \mathrm{kV}$ to $33.000 \mathrm{kV}$ respectively. The IEEE 14 bus system has higher bus voltage thus better stability when the STATCOM and ESS were applied at bus 14 compared to system without STATCOM and ESS. The STATCOM was able to supply the required reactive power while the ESS was able to compensate sufficient reactive energy towards the system in order to improve the power system stability. In this research, the interrelation between the purposed sizing and placement of STATCOM and ESS with the IEEE 14 bus system has been examined. The main focus for this research is to examine the effect of installing the STATCOM and ESS for power system stability improvement. The power system stability improvement has been successfully achieved by placing the STATCOM and ESS at the most vulnerable bus, which is at bus 14. The sizing of the STATCOM and ESS were determined during the conduction of simulation to ensure the effectiveness of each sizing. The simulation results verified the correct sizing and placement of STATCOM and ESS towards the improvement of power system stability. The impact of the sizing and placement of STATCOM and ESS has been discussed in case of increase of system loadability. The proposed system executes successfully.

\section{ACKNOWLEDGEMENT}

The authors would like to express their gratitude to Universiti Kuala Lumpur for supporting and funding this research under grant No. str18005.

\section{REFERENCES}

[1] G. K. Stefopoulos and A. Meliopoulos, "Induction motor load dynamics: Impact on voltage recovery phenomena," in Proceedings of the 2005/2006 IEEE Transmission and Distribution Conference and Exposition, pp. 752-759, 2006.

[2] K. Yahya, M. Z. Bilgin, and T. Erfidan, "Practical implementation of maximum power tracking based short-current pulse method for thermoelectric generators systems," Journal of Power Electronics, vol. 18, pp. 1201-1210, 2018.

[3] M. H. Alsharif, K. Yahya, and Z. W. Geem, "Strategic Market Growth and Policy Recommendations for Sustainable Solar Energy Deployment in South Korea," Journal of Electrical Engineering \& Technology, pp. 1-13, 2019.

[4] Y. M. Atwa and E. El-Saadany, "Optimal allocation of ESS in distribution systems with a high penetration of wind energy," IEEE Transactions on Power Systems, vol. 25, pp. 1815-1822, 2010.

[5] P. Kundur, J. Paserba, V. Ajjarapu, G. Andersson, A. Bose, C. Canizares, et al., "Definition and classification of power system stability," IEEE transactions on Power Systems, vol. 19, pp. 1387-1401, 2004.

[6] F. Dong, B. H. Chowdhury, M. L. Crow, and L. Acar, "Improving voltage stability by reactive power reserve management," IEEE transactions on Power Systems, vol. 20, pp. 338-345, 2005.

[7] P. Srithorn, M. Sumner, L. Yao, and R. Parashar, "Power system stabilisation using STATCOM with supercapacitors," in 2008 IEEE Industry Applications Society Annual Meeting, pp. 1-8, 2008.

[8] B. Ismail, M. M. Naain, N. I. A. Wahab, L. J. Awalin, I. Alhamrouni, N. H. A. Rahman, et al., "Short circuit current and voltage sag profile studies for optimal location of DG in distribution network," in AIP Conference Proceedings, p. 020136, 2019.

A. Jain, K. Joshi, A. Behal, and N. Mohan, "Voltage regulation with STATCOMs: modeling, control and results," IEEE Transactions on Power delivery, vol. 21, pp. 726-735, 2006.

[9] X.-P. Zhang, C. Rehtanz, and B. Pal, "Flexible AC transmission systems: modelling and control", Springer Science \& Business Media, 2012.

[10] P. Srithorn, "Power System Stabilisation Using STATCOM with Supercapacitors," Industry Aplications Society Annual Meeting IEEE, 2008.

[11] M. M. Almelian, I. Mohd, A. Z. Ahmad, M. Salem, M. A. Omran, A. Jusoh, et al., "Enhancing the performance of cascaded three-level VSC STATCOM by ANN controller with SVPWM integegration," International Journal of Electrical \& Computer Engineering (IJECE), vol. 9, pp. 3880-3890, 2019.

[12] K. J. A. Jain, "Voltage regulation with statcoms: Modeling, control and results," Power Delivery, IEEE Transactions, pp. 726-735, 2006.

[13] e. a. X.-P. Zhang, "Flexible AC Transmission Systems: Modelling and Control”., 2005. 
[14] M. A. A. Ibrahim Alhamrouni, Bazilah Ismail, Mohamed Salem, Awang Jusoh, T. Sutikno "Load Flow Based Voltage Stability Indices for Voltage Stability and Contingency Analysis for Optimal Location of STATCOM in Distribution Network with Integrated Distributed Generation Unit," TELKOMNIKA (Telecommunication Computing Electronics and Control), vol. 16, p. 14, 2018.

[15] B. Ismail, M. M. Naain, N. I. A. Wahab, L. J. Awalin, I. Alhamrouni, and M. F. A. Rahim, "Optimal placement of DSTATCOM in distribution network based on load flow and voltage stability indices studies," in 2017 International Conference on Engineering Technology and Technopreneurship (ICE2T), pp. 1-6, 2017.

[16] H. e. Chen, "Progress in electrical energy storage system: A critical review," Progress in Natural Science, pp. 291-312, 2009.

[17] M. Salem, A. Jusoh, N. R. N. Idris, H. S. Das, and I. Alhamrouni, "Resonant power converters with respect to passive storage (LC) elements and control techniques-An overview," Renewable and Sustainable Energy Reviews, vol. 91, pp. 504-520, 2018.

[18] M. A. Omran, I. I. Ibrahim, A. Z. Ahmad, M. Salem, M. M. Almelian, A. Jusoh, et al., "Comparisons of PI and ANN controllers for shunt HPF based on STF-PQ Algorithm under distorted grid voltage," Int J Pow Elec \& Dri Syst, vol. 10, pp. 1339-1346, 2019.

[19] G. W. Babazadeh H, "A new control scheme in a battery energy storage system for wind turbine generators," Proceedings of IEEE Power and Energy Society General Meeting, IEEE, pp. 1-7, 2012.

[20] F. J. Jenkins DP, "Lifetime prediction and sizing of lead-acid batteries for microgeneration storage applications," IET Renewable Power Generation, pp. 191-200, 2018.

[21] B. Ismail, M. M. Naain, N. I. A. Wahab, N. S. M. Shaberon, L. J. Awalin, and I. Alhamrouni, "Voltage stability indices studies on optimal location of wind farm in distribution network," in 2017 IEEE Conference on Energy Conversion (CENCON), pp. 111-116, 2017.

[22] Alhamrouni, M. Rahmat, F. Ismail, M. Salem, A. Jusoh, and T. Sutikno, "Design and development of SEPIC DCDC boost converter for photovoltaic application," Int J Pow Elec \& Dri Syst, 2019.

[23] Alhamrouni, N. Zainuddin, M. Salem, N. H. Rahman, and L. Awalin, "Design of single-phase inverter for photovoltaic application controlled with sinusoidal pulse width modulation," Indonesian Journal of Electrical Engineering and Computer Science (IJEECS), vol. 15, pp. 620-630, 2019.

[24] M. International, IEEE 14 Bus System. Winnipeg, Manitoba: Manitoba Hydro International Ltd., 2018.

[25] F. M. Albatsh, "Weakest Location Exploration in IEEE-14 Bus System for Voltage Stability Improvement Using STATCOM, Synchronous Condenser and Static Capacitor," International Conference on Electrical, Computer and Communication Engineering (ECCE), pp. 623-629, 2017.

[26] M. Y. S. A. Anbarasan, "Voltage Stability Improvement In Power System By Using STATCOM," International Journal of Engineering Science and Technology (IJEST), vol. 4, pp. 4584-4597, 2014. 